Egyptian Journal of Aquatic Biology \& Fisheries

Zoology Department, Faculty of Science,

Ain Shams University, Cairo, Egypt.

ISSN $1110-6131$

Vol. 24(4): 521 - 534 (2020)

www.ejabf.journals.ekb.eg

\title{
Biodiversity patterns along seasonality and environmental factors of stream macroinvertebrate communities of North-Central Nigeria
}

\author{
Unique Keke $^{1, *}$, Francis Arimoro ${ }^{1}$, Adesola Ayanwale ${ }^{1}$, Oghenekaro Odume $^{2}$ and \\ Augustine Edegbene ${ }^{2}$
}

${ }^{1}$ Applied Hydrobiology Unit, Department of Animal Biological, Federal University of Technology, Minna, Nigeria

${ }^{2}$ Unilever Centre for Environmental Water Quality, Institute for Water Research, Rhodes University, P. O. Box 94 Makhanda (Grahamstown), South Africa

*Corresponding Author: n.keke@futminna.edu.ng; uniquekkn@gmail.com

\section{ARTICLE INFO}

Article History:

Received: June 1, 2020

Accepted: July 8, 2020

Online: July 10, 2020

Keywords:

Afrotropical,

Biodiversity,

Macroinvertebrates,

Conservation;

Temporal variation,

Variabilities

\begin{abstract}
While there is a substantial increase in the number of studies investigating the biodiversity of the Afrotropical region, the influence of season on biodiversity is still poorly understood. The biodiversity patterns of 15 streams along with seasonality and environmental correlates were explored from 2016 - 2017. Biodiversity variables were calculated using diversity functions in vegan, including beta diversity partitioning. Seasonal variations in biodiversity and community-environment relationships were calculated using Mann-Whitney-Wilcoxon tests and distance-based redundancy analysis (dbRDA). While alpha diversity was low, beta diversity was relatively high and promoted by its turnover component. In spite of the clear seasonal variabilities of the region, biodiversity variables did not differ between seasons, suggesting that temporal variation was not a key factor in structuring the streams macroinvertebrates. The results suggest that seasonal variations in biodiversity may be confounded by multiple factors, including possible overridden influence from the regional perspective of biodiversity. In order to establish reliable biomonitoring and conservation programs for biodiversity, studies from different seasons should be considered, especially regions rich in biodiversity.
\end{abstract}

\section{INTRODUCTION}

Biodiversity distribution across the Earth is heterogenous. Alpha and Beta diversity components of biodiversity interact with the gradients of each other, and the two biodiversity components are a result of assemblage of communities from local and regional dynamics. Thus, the dynamic nature of biodiversity patterns may be well captured by an integration of both alpha and beta components of biodiversity, other than the simplistic measurement of alpha diversity alone (Soininen $\boldsymbol{e t}$ al., 2017). 
In recent times, beta diversity is considered an important metric in informing regional biodiversity patterns and also contributes to efficient and effective biodiversity conservation strategy (Socolar et al., 2016). There are two components of beta diversity, namely turnover and nestedness. Turnover refers to species replacement while nestedness is related to species loss or gain (Baselga, 2010). Naturally, species turnover can indicate species sorting occasioned by environmental or dispersal mechanisms, while nestednes is usually connected to ordered extinction-colonization mechanisms (Si et al., 2016). If local habitat conditions determine local diversity, and there is a high degree of species turnover among sites, then it is infact regional species richness that mirrors variation in local species richness across a region. In order to effectively guarantee both environmental assessment and conservation, the knowledge of biodiversity dynamics of several under-studied metrics is needed (Leather, 2009; Heino et al., 2015). Secondly, more information about gamma diversity, alpha diversity, and beta diversity at the different scales would be important (Heino, 2013; Bini et al., 2014), since understanding regional biodiversity dynamics is amongst the first steps to effectively conserve and restore ecosystems (Angeler and Drakare, 2013).

Freshwater bodies are among the most-threatened ecological systems of the globe (Arimoro and Keke, 2017; Edegbene et al., 2020). Streams and rivers in the tropics are recognised as important resources for global biodiversity preservation and protection (Arimoro et al., 2015; Tonkin et al., 2016). Given that processes such as eutrophication, loss of habitat and climate change are increasingly impairing ecological systems, there is urgency to understand biodiversity dynamic patterns of most tropical freshwater ecosystem, especially the Afrotropics inspite of its importance in accounting for the biodiversity of the world ((Heino et al., 2015; Tonkin et al., 2016; Alahuhta et al., 2017).

Strong variations in rainfall regime between wet and dry seasons are major characteristics of tropical streams (Boyero et al., 2015). Thus, distribution of macroinvertebrate communities is controlled by the rainfall seasonality. In this regard, seasonal variability of macroinvertebrate community needs consideration in order to establish reliable biomonitoring programs (Al-Shami et al., 2013). Typically, variations in community structures and population decline may be among some adverse effects of flow discharges (Boyero et al., 2015). Though they may be very predictable, high spates and flood are generalized as environmental disturbances given their large magnitude as well as their geomorphological actions. Certain swift and quick responses could make a headwater stream change its form - from a quiet, slow-moving stream to a torrent - in just a few hours (Mesa, 2010). During the seasons of high waters with flow instability, flow patterns generate a physical formula that controls the lotic dynamics. Conversely, during the seasons of low flow regime, characterized by habitat and volume reduction, the strength of interactions between the biota seems to be temporally important. This is especially when the habitat area and volume reduction are not particularly important in eliciting some forms of behavioral and physiological upset that would force organisms to make certain individual physiological adjustments to accommodate the changing environmental condition (Mesa, 2012). 
Even though biodiversity studies are increasing being considered in the tropical regions, the relationships between biodiversity and seasonality have not been thoroughly investigated, particularly in the Afrotropical region. A study on the biodiversity distribution patterns of macroinvertebrate traits in relation to seasonality is pertinent to gain insight into how seasonal environmental changes may confer adaptation traits to macroinvertebrates. This is particularly important given that tropical streams are extremely dynamic in nature, with strong seasonality assuming a vital component in community structuring (Tonkin et al., 2016).

North Central Nigeria is of international importance being highly heterogeneous at all spatial scales, considered a biodiversity hotspot, and hosts the dams that generate electricity to some contiguous countries. Despite its importance, a broad suite of studies has demonstrated diversity-environment interactions and seasonality on local scales, and no study has galvanized such interactions in large-scale related dynamics. Therefore, the aim of this study was to explore the biodiversity accounts of an important tropical ecosystem along seasonality and environmental correlates, with a view to aiding the development of framework for management of biodiversity in the North-Central ecoregion of Nigeria.

\section{MATERIALS AND METHODS}

\section{Study area}

The studied streams are situtated in Niger State within the North Central ecoregion of Nigeria. The tropical climates of two distinct seasons: the dry season (November-March) and the wet season (April-October) characterize the study area. Major land use in the stream catchments include sand mining, irrigation farming and indiscriminate defecation. Fishing in the area is characterized by artisanal fisher folks that use manually operated wooden (dug out) canoes. Natural vegetation and mosaic of cropland mainly constitute the land use practices in the catchment.

\section{Sampling of the study sites}

Fifteen (15) streams were sampled for twenty-four (24) months (2016 and 2017; Figure 1). The sampled streams were Baka-Jeba (BJ), Chanchaga (CH), Chike (CE), Gada (GA), Gbako (GB), Grigada (GR), Gurara (GU), Kaduna (KD), Kataeregi (KA), Landzun (LA), Musa (MU), Penyan (PE), Samu (SA), Wushishi (WU), and Wuya (WY). Each stream was sampled four times within a period of one year, representing two sampling per season each year. This process was repeated the following year. Some priority environmental variables (i.e. physico-chemical variables) were assessed simultaneously with macroinvertebrates sampling. To ensure that some sets of potentially interacting species were being surveyed, we ensured that sampling of benthic macroinvertebrates was carried out within a single period of time. 


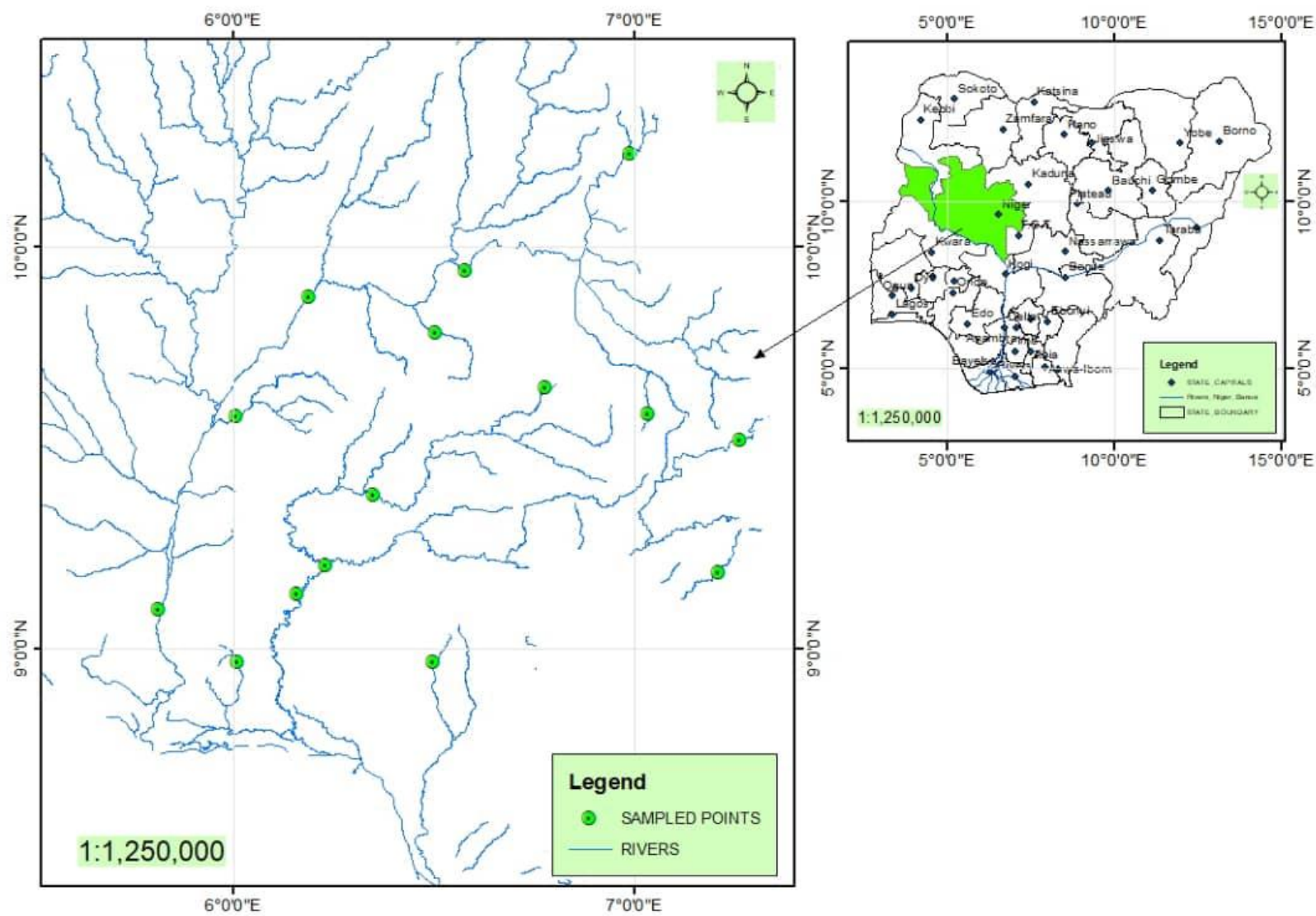

Figure 1: A map of the study area showing sampled locations

Source: Geography department, Federal University of Technology, Minna, Nigeria.

\section{Environmental variables}

Depth was measured with a calibrated rod. Canopy cover was measured by visually estimating the percentage cover along the sampled reaches. The substratum composition in each of the sampled stretches was measured by visually estimating the percentage of sand, mud, silt, clay, and loan contained (Ward, 1992). Shading by overhanging vegetation was measured as percentage cover at 20 locations in evenly spaced crosschannel transects, including percentage macropytes, and woods/logs (Ward, 1992). About 10 randomly spaced $50 \mathrm{~cm} \times 50 \mathrm{~cm}$ quadrats were used to assess the moss cover. The average of the estimates from each quadrat was considered the mean substratum particle size for a site. Dissolved oxygen meter (YSI 55 dissolved meter) was used in measuring DO at each sampling site, while water temperature, $\mathrm{pH}$ and $\mathrm{EC}$ were measured using a portable multiparameter device (HANNA HI 9913001/1). Water samples were collected in $500 \mathrm{ml}$ sterile glass bottle and, samples were analysed for nitrate, phosphate and $\mathrm{BOD}_{5}$ according to APHA (1995) method.

\section{Macroinvertebrate sampling and processing}

Benthic macroinvertebrates samples were collected from a 100-m stream reach using a $0.09-\mathrm{m}^{2}$ surber sampler with a $250-\mu \mathrm{m}$ mesh size. The collection method ensured the 
three microhabitats/flow regimes (the pools, riffles, and runs) and all the different substrata (vegetation, sand, gravel biotopes, etc) were included. In order to avoid bias, three random samples were collected from each of the three microhabitats for a total of three times, and then pooled to form one composite sample per station. To ensure that all microhabitats were adequately sampled, the three microhabitats per sampling event per site were pooled into one composite sample. The collected samples were preserved in a $10 \%$ formaldehyde solution and transported to the laboratory for sorting and subsequent identification. In the laboratory, samples were washed in a 500-mm mesh sieve to remove sediment and macroinvertebrates were sorted using a stereoscopic microscope (magnification x10). All animals were separated, enumerated and identified under a binocular dissecting microscope. All sorted macroinvertebrates were identified to the lowest taxonomic level possible using Merritt and Cummins (1996), Day et al., (2002) and De Moor et al., (2003). References were made to the taxonomic lists of species known to be present in Nigeria (e.g. Arimoro and James, 2008; Arimoro et al., 2012).

\section{Data analysis}

For the alpha diversity patterns, mean local taxonomic richness, abundance, and the Shannon diversity index for each site in each season were calculated. The Shannon index was calculated using the 'diversity' function in vegan. Seasonal differences in richness, abundance, and Shannon diversity were tested using Mann-Whitney-Wilcoxon tests, with the function 'wilcox.test' due to non-normality after checking for normality using Shapiro-Wilks test and inspecting qqplots and residuals (Tonkin et al., 2016).

Beta-diversity based on multiple sites of the rainy and dry seasons was calculated. Distance-based redundancy analysis (dbRDA; Legendre and Anderson, 1999) was used to examine seasonal variations in each component of beta diversity. Dissimilarity matrices based on species presence-absence data were obtained using the function "beta.pair" in the R package betapart (Baselga et al., 2017). The index used is a monotonic transformation of a Sørensen index, in which turnover and nestedness can be separated (Baselga, 2010, 2012). This function produces three multiple-site dissimilarity matrices, namely: Sørensen (total), Simpson (turnover) and nestedness matrices. These resulting matrices were employed as response variables in dbRDA.

The Community-environment relationships were evaluated using the distancebased redundancy analysis (dbRDA; Legendre and Anderson 1999). dbRDA as a constrained ordination method is an extension of the original RDA that is based on Euclidean distances (Legendre and Legendre, 1998) and can use any type of distance matrix as the response. Legendre and Legendre (1998) showed that RDA could be used as a form of ANOVA which was applicable to community composition data if they were transformed in some appropriate way, which went through the calculation of a dissimilarity matrix of the user's choice. For this purpose, this approach remains fully valid and useful for all dissimilarity and distance measures that cannot be obtained by a data transformation, followed by the calculation of the Euclidean distance. 


\section{RESULTS}

A total of 9,740 macroinvertebrate individuals from 125 taxa were recorded from the streams sampled across the two seasons (wet and dry). The range of taxonomic richness was between 19 and 73 per site, with an average of $31.2 \pm 4.1$ (S.E) for the dry season. For the wet season, the range of species richness was between 14 and 66, with an average of $25.5 \pm 2.6$ (S.E). However, there was no significant difference $(\mathrm{P}<0.05)$ between the species richness values of the wet and dry seasons (Fig. 2a). Similarly, abundance per site and Shannon diversity values did not differ $(\mathrm{P}<0.05)$ between the dry and wet seasons (Fig. 2b and Fig. 2c), even though more organisms were recorded during the dry season sampling.

A

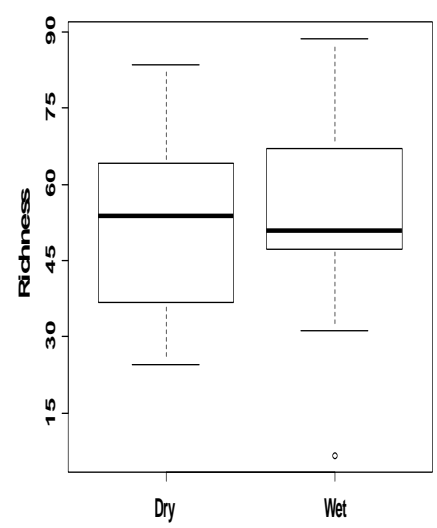

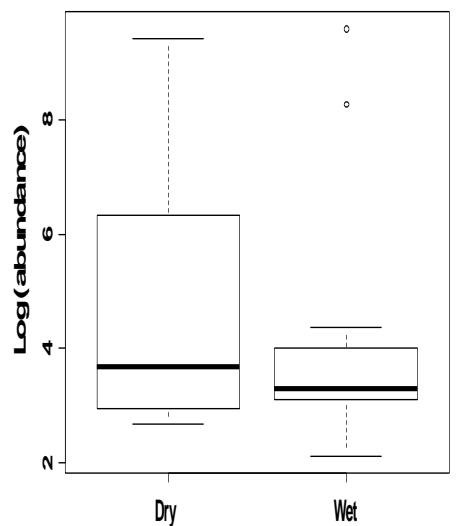

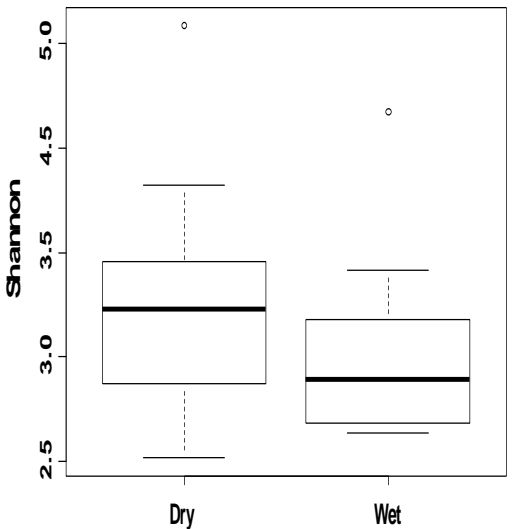

Fig. 2: Differences in taxonomic richness, $P=0.221$ (a); abundance, $P=0.176$ (b); and Shannon diversity index, $P=0.203$ (c) between wet and dry seasons of benthic macroinvertebrates communities in 15 streams of the North Central region of Nigeria.

The macroinvertebrates communities showed relatively high levels of beta diversity for both dry and wet seasons. For the two seasons (wet and dry), the distance to centroids revealed that the total beta diversity (Sørensen) and variations in community structure were driven by the turnover component (Simpson) while the nestedness component (Simpson) was almost negligible (Fig. 3). Beta diversity did not differ between seasons as shown by the average distance to centroid for Sørensen, Simpson (turnover), and nestedness components of beta diversity (Fig. 4).

The invertebrates community pattern was linked slightly more strongly to environmental variables in the dry season ordination model than in the rainy season (Fig. 5), as environmental predictors accounted for about $59 \%$ of variations in community structure during the dry season, while $54.1 \%$ of variation in community structure was accounted for by the environmental variables during the rainy season. The environmental predictors that were most influential in community structuring during the rainy season were conductivity, nitrates, depth, and temperature. Conversely, $\mathrm{pH}$, nitrates, phosphates, and dissolved oxygen were the environmental predictors that were most influential in explaining variations observed in community structure during the dry season. Nitrates 
appeared as the only environmental predictor that the constraint ordination model picked for both seasons ordination. Nonetheless, nitrate was negatively correlated with community structure during the rainy season (axis 1), while it was positively correlated with community structure during the dry season.
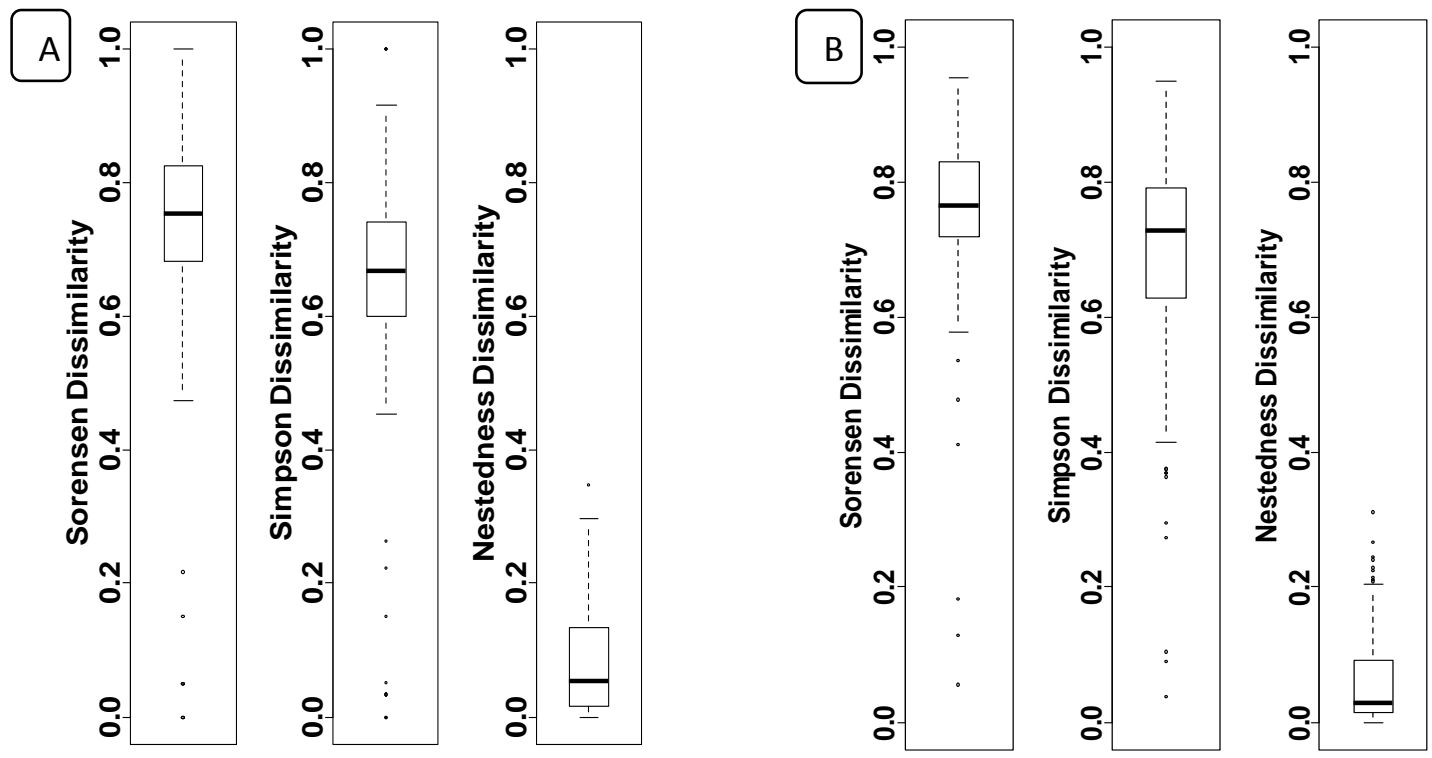

Fig. 3: Boxplots partitioning beta diversity into overall (Sorensen), and turnover and nestedness components for benthic macroinvertebrates sampled from 15 streams in Niger State, Nigeria, in each of the dry (A) and wet seasons (B). Analyses are based on presenceabsence data.
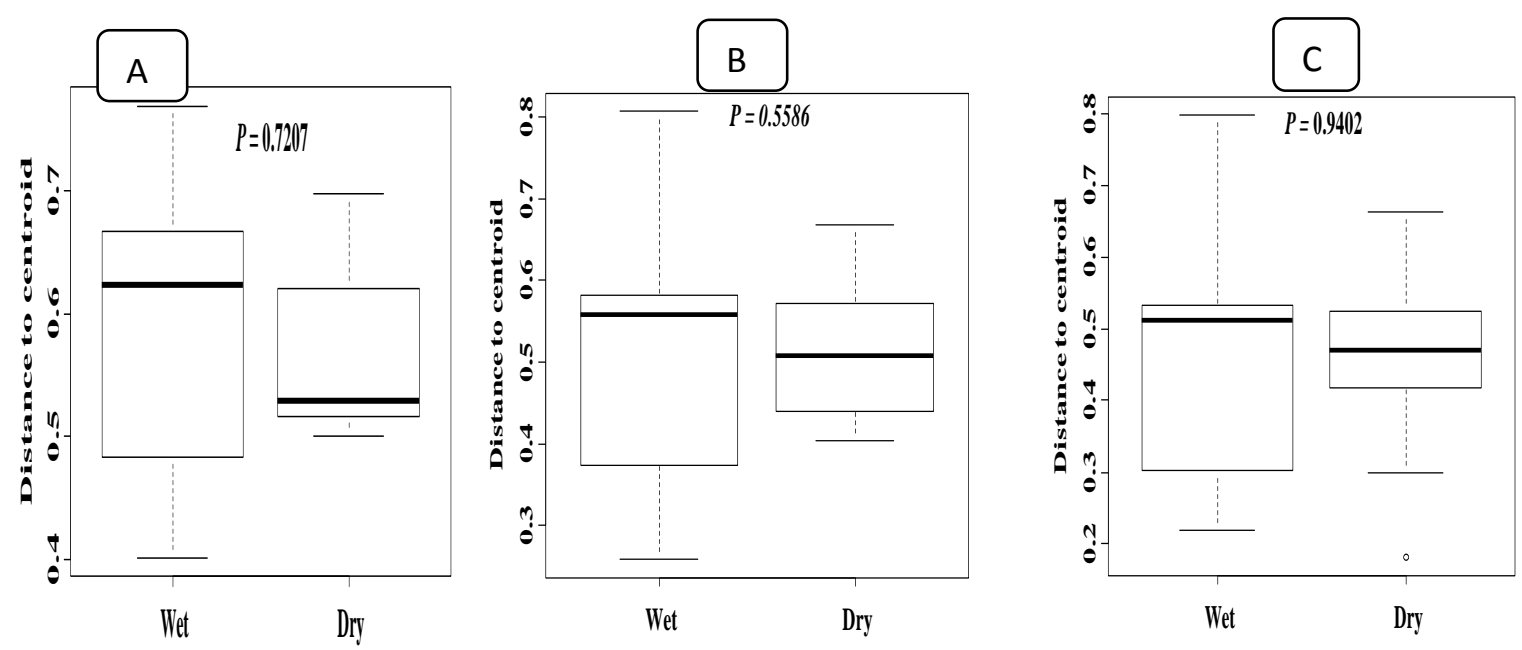

Fig. 4: Differences in beta diversity between wet and dry seasons of benthic macroinvertebrates communities of 15 streams of the North Central region of Nigeria using overall (Sorensen), and turnover and nestedness components of beta diversity. 

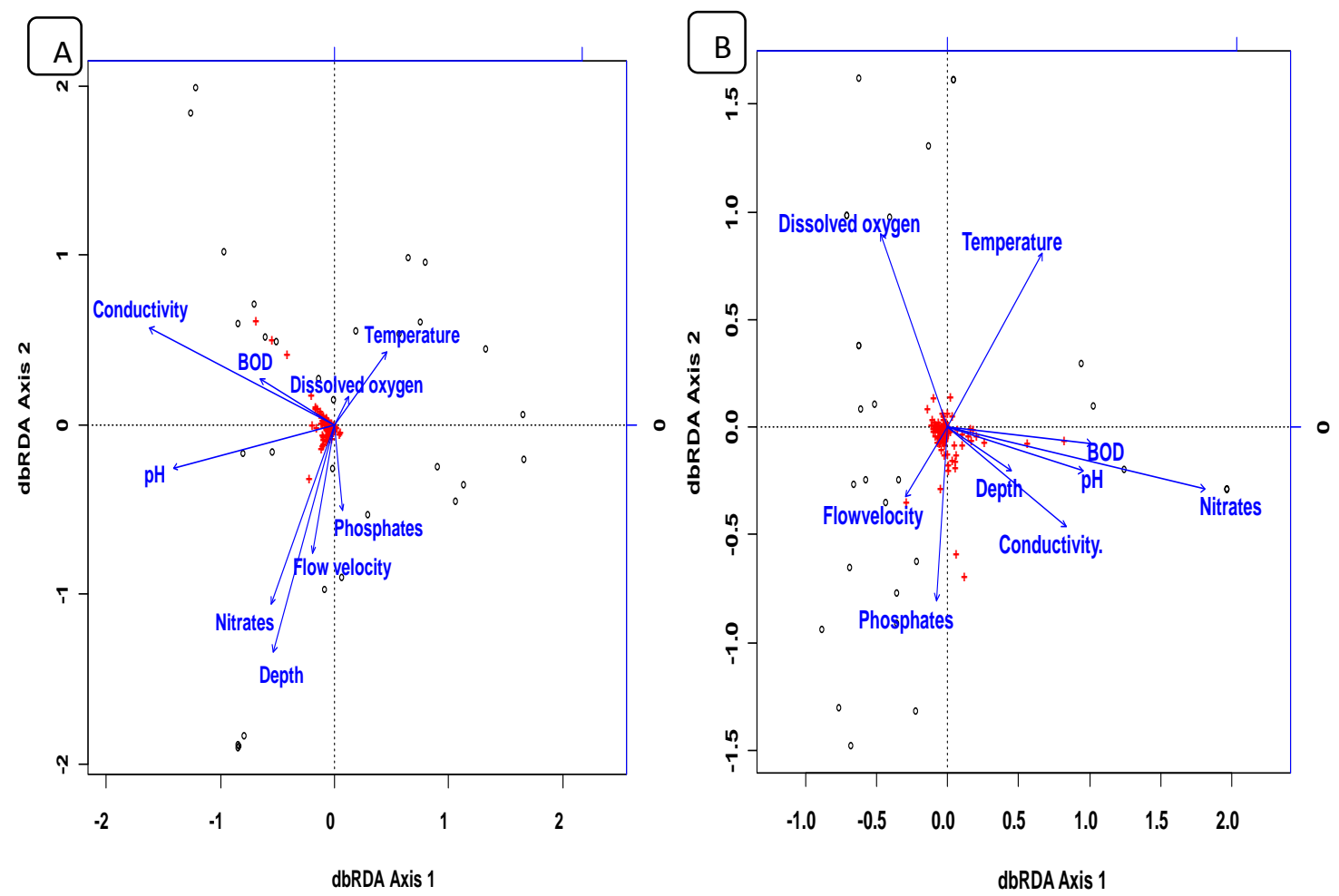

Fig. 5: Distance-based Redundancy Analysis (dbRDA) ordination plots of the importance of environmental variables to the community structuring of benthic macroinvertebrates of 15 streams of the North Central region of Nigeria during the wet season (A) and dry season (B).

\section{DISCUSSION}

This study found relatively low alpha diversity, but high beta diversity and this would contribute to high regional biodiversity. Given that the understudied region is dubbed hotspot of biodiversity (Tonkin et al., 2016), as well as the vast variations between the temperate and tropical aquatic biotic communities, it was surprising that the alpha diversity was low. The outcome of low alpha diversity with high beta diversity probably shows a high degree of variations in environmental factors given that regional variations in beta diversity is chiefly determined by heterogeity of habitat (Heino et al., 2015; Tonkin et al., 2016). This is further buttressed by the paucity of clear patterns of environmental factors recorded across the streams from this present research. However, the findings of Tonkin et al (2016) who explored stream communities in Niger Delta area of Nigeria observed similar record of low alpha and high beta diversities. Similarly, the study of Vinson and Hawkins (2003) did not observe any obvious latitudinal gradient in Ephemeroptera, Plecoptera, and Tricoptera. Total beta diversity was mostly structured by strong turnover component of beta-diversity, while the nestedness effect was almost negligible. Species turnover can indicate species sorting occasioned by environmental or dispersal mechanisms, while nestednes is usually connected to ordered 
extinction-colonization mechanisms (Si et al., 2016). Turnover obviously dominated in majority of the studies that partitioned beta diversity, indicating limited effects of richness difference in structuring patterns of beta diversity (Tisseuil et al., 2012; Viana et al., 2016). This typifies majority of studies across local ecosystems, while strong nestedness is typical of most large-scale ecosystem studies (Soininen et al., 2017). Specifically, strongest accounts of nestedness are usually recorded at very large extents (such as continents and the globe), since extinction-colonization mechanisms are more effective only at these large extents, creating alpha diversity slopes (Dobrovolski $\boldsymbol{e t}$ al., 2012; Soininen et al., 2017). Given that our study covered a small spatial extent, species sorting by the environmental condition, other than dispersal limitation, may have influenced the strong turnover that structured the macroinvertebrates communities in our study. Landeiro et al (2012) and Al-Shami et al (2013) also observed stronger roles of environmental factors in structuring the beta diversity patterns of Amazonian and Brazillian streams, respectively. Conversely, Tonkin et al., (2016) had observed the stronger influence of dispersal limitation in structuring benthic macroinvertebrate communities of the Niger Delta area, given that their study spanned across relatively large extent.

Several surveys of most tropical streams have demonstrated that biodiversity accounts in tropical streams are strongly influenced by alterations in environmental variables between seasons (Leung et al., 2012; Boyero et al., 2015; Tonkin et al., 2016;). The overall biodiversity patterns of alpha and beta diversity did not differ between the wet and dry seasons, and this was surprising given the strong differences between the wet and dry season in terms of rainfall dynamics in the tropics, particularly the Afrotropics. Although overall biodiversity patterns did not differ between seasons, there were obvious variations between seasons in individual community composition considered. This probably could suggest overridden and counterracting effect of regional variation over within-stream local variation. It is also plausible to state that various year-to-year changes in climate and environmental conditions may have affected any possibility of detecting overall seasonal changes in biodiversity, given that our sample collection covered more than one wet-dry seasonal regime. This outcome was not surprising given that aquatic biotic community is determined by a multitude of factors existing at different spatial extents (Heino et al., 2015; Horta et al., 2016). Tonkin et al., (2016), who explored patterns of stream communities in the Niger Delta area of Nigeria, also observed lack of any clear variabilities in biodiversity dynamics between the two seasons. Similarly, Keke $\boldsymbol{e t}$ al., (2017) observed that although there were $53 \%$ and $47 \%$ variations in stream communities for dry and rainy seasons, respectively, there was no significant difference between the seasonal species richness in an earlier univariate survey of one of the streams considered in this multivariate approach (Gbako River).

Although benthic macroinvertebrates community was linked slightly more strongly to environmental variables in the dry season ordination model than in the rainy season, the important variables differed between them. This lack of clear gradients between the environmental variables clearly reflects the idea about the dearth of environmental predictors of macroinvertebrates community structure in the Afrotropics. This is in agreement with the paucity of clear-cut environmental drivers of community structure demonstrated by recent surveys in the Afrotropical region (Kasangaki et al., 2008; 
Arimoro et al., 2012; Masese et al., 2014; Tonkin et al., 2016; Keke et al., 2017). Both antagonistic and synergistic contributions of these variables can be employed in identifying and describing the multiple-scale stressor. There were also correlations of many individual environmental variables with the axes that were high for the dbRDA but were not statistically significant. In other words, their assumed significances may have co-varied with the significance of some environmental variables that were not measured.

Although variations in conductivity and flow regime can be natural fluvial occurrences, they can also act as potential stressors with strong effects on aquatic biodiversity and ecosystem dynamics (Mustonen $\boldsymbol{e t}$ al., 2016). In spite of the fundamental importance of natural flow dynamics to freshwater ecosystem integrity, anthropogenic-induced changes on the natural flow processes are also considered as strong drivers in flowing water ecosystem (Poff and Zimmerman 2010). Both flow and conductivity may have both antagonistic and synergistic effects on macroinvertebrates biotic community. For instance, during periods of low flow, concentration effects on the substratum could increase the conductivity level of the water, causing strong negative effects on stream biotic composition (Mustonen et al., 2016). Also, the dilution effects of high flow could alter the conductivity concentrations of the water, resulting to abrasion with accompanying negative or positive effect on constituent invertebrates. Again, uncontrolled cutting of riparian forest also changes canopy shading, which in turn, affects the benthic macroinvertebrates apha diversity (species richness) and overall community productivity (Boyero et al., 2016). For several freshwater macroinvertebrates, the riparian vegetation constitutes a very fundamental predictor of life. However, unfortunately, their ecological influences are only given rare considerations in recent freshwater studies (Boyero et al., 2015).

\section{CONCLUSION}

This preliminary study has demonstrated that the biodiversity of the north central region of Nigeria is driven by the turnover component. Inspite of the clear seasonal variabilities of the region, temporal variation was not a key factor in structuring biodiversity. Our results suggest that seasonal biodiversity variations may be confounded by multiple factors such as the overridden influence from regional components of biodiversity. In order to establish reliable biomonitoring and conservation programs for biodiversity, studies from different seasons should be considered along with the inclusion of local and regional datasets, especially for this region being a biodiversity hotspot.

\section{Acknowledgements}

Professor Jani Heino of Biodiversity Unit, Finnish Environment Institute (SYKE), Natural Environment Centre, Oulu, Finland was helpful in providing advice and feedback with aspects of beta-diversity in R. We also acknowledge two anonymous referees/ reviewers for constructive comments on a previous version of the manuscript. 


\section{Funding}

This work was supported by the International Foundation for Science, Sweden in a grant given to the first author (IFS ref: I-2-A-6209-1)

\section{Declaration of competing interests}

The authors declare that they have no conflict of interest.

\section{REFERENCES}

Alahuhta, J.; Kosten, S.; Akasaka, M.; Auderset, D.; Azzella, M.; Bolpagni, R. and Heino, J. (2017). Global variation in the beta diversity of lake macrophytes is driven by environmental heterogeneity rather than latitude. Journal of Biogeography, 44: 1758-1769.

Al-Shami, S. A.; Heino, J. and Che Salmah, M. R. (2013). Drivers of beta diversity of macroinvertebrate communities in tropical forest streams. Freshwater Biology 58:1126-1137.

Angeler, D. G. and Drakare, S. (2013). Tracing alpha, beta and gamma diversity responses to environmental change in boreal lakes. Oecologia 172:1191-1202.

APHA. (1995). Standard methods for the examination of water and wastewater. American Public Health Association, Washington, DC

Arimoro, F. O. and Keke, U. N. (2017). The intensity of human-induced impacts on the distribution and diversity of macroinvertebrates and water quality of Gbako River, North Central, Nigeria. Energy, Ecology and Environment 2(2):143-154.

Arimoro, F. O. and James, H. M. (2008). Preliminary pictorial guide to the macroinvertebrates of Delta State Rivers, Southern Nigeria. Grahamstown: Albany Museum

Arimoro. F. O.; Obi-Iyeke, G. E.; Obukeni, P. J. O. (2012). Spatiotemporal variation of macroinvertebrates in relation to canopy cover and other environmental factors in Eriora River, Niger Delta, Nigeria. Environmental Monitoring Assessment 184: 6449-6461

Arimoro, F. O.; Odume, O. N.; Uhunoma, S. I. and Edegbene, A. O. (2015). Anthropogenic impact on water chemistry and benthic macroinvertebrate associated changes in a southern Nigeria stream. Environmental Monitoring and Assessment 187:1-14

Baselga, A. (2010) Partitioning the turnover and nestedness components of beta diversity. Global Ecology and Biogeography 19: 134-143

Baselga, A.; Gomez-Rodríguez, C. and Lobo, J. M. (2012). Historical legacies in world amphibian diversity revealed by the turnover and nestedness components of beta diversity. PLoS One e32341 
Baselga, A.; Orme, D.; Villeger, S.; De Bortoli, J. and Leprieur, F. (2017). Package "betapart". Partitioning beta diversity into turnover and nestedness components [Version 1.4-1]. Retrieved from https://cran.r-project. org/web/packages/betapart

Bini, L. M.; Diniz-Filho, J. A. F. and Hawkins, B. A. (2014). Macroecological explanations for differences in species richness gradients: a canonical analysis of South American birds. Journal of Biogeography 31: 1819-1827.

Boyero, L.; Pearson, R. G. and Gessner, M. O. (2015). Leaf-litter breakdown in tropical streams: is variability the norm? Freshwater Science doi:10.1086/681093

Day, J. A.; Harrison, A. D. and De Moor, I. J. (2002). Guides to the freshwater invertebrates of Southern Africa, vol. 9, DipteraTT 201/02 Pretoria: Water Research Commission

De Moor, I. J.; Day, J. A. and De Moor, F. C. (2003). Guides to the freshwater invertebrates of Southern Africa, vol. 7. Insecta I (Ephemeroptera, Odonata and Plecoptera) TT. Pretoria: Water Research Commission

Dobrovolski, R.; Melo, A. S.; Cassemiro, F. A. S. and Diniz-Filho, J. A. F. (2012). Climatic history and dispersal ability explain the relative importance of turnover and nestedness components of beta diversity. Global Ecology and Biogeography 21: 191-197

Edegbene, A. O.; Arimoro, F. O. and Odume, O. N. (2020). Exploring the distribution patterns of macroinvertebrate signature traits and ecological preferences and their responses to urban and agricultural pollution in selected rivers in the Niger Delta ecoregion, Nigeria. Aquatic Ecology https://doi.org/10.1007/s10452-020-09759-9

Heino, J.; Gronroos, M.; Ilmonen, J.; Karhu, T.; Niva, M. and Paasivirta, L. (2013). Environmental heterogeineity and $\beta$ diversity of stream macroinvertebrate communities at intermediate spatial scales. Freshwater Science 32:412-154.

Heino, J.; Melo, AS.; Siqueira, T.; Soininen, J.; Valanko, S. and Bini, L. M. (2015). Metacommunity organisation, spatial extent and dispersal in aquatic systems: patterns, processes and prospects. Freshwater Biology 21: 45-56

Horta, F.; Santos, H.; Tavares, L.; Antunes, M.; Pinheiro, P. and Callisto, M. (2016). Assessment of benthic macroinvertebrate habitat suitability in a tropical watershed. Tropical Ecology 3: 1-10.

Kasangaki, A.; Chapman, L. and Balirwa, J. (2018). Land use and the ecology of benthic macroinvertebrate assemblages of high-altitude rainforest streams in Uganda. Freshwater Biology 53:681-697.

Keke, U. N.; Arimoro, F. O.; Auta, Y. I. and Ayanwale, A. V. (2017). Temporal and Spatial variability in Macroinvertebrate community structure in relation to environmental variables in Gbako River, Niger State, Nigeria. Tropical Ecology 58: 229-240. 
Keke, U. N.; Arimoro, F. O., Ayanwale, A.V. and Aliyu, S. M. (2015). Physicochemical parameters and heavy metals content of surface water in downstream Kaduna River, Zungeru, Niger state, Nigeria. Applied Science Research Journal 3: 46 -57.

Landeiro, V. L.; Bini, L. M. and Melo, A. S. (2012). The roles of dispersal limitation and environmental conditions in controlling caddisfly (Trichoptera) assemblages. Freshwater Biology 57:1554-1564.

Leather, S. R. (2009). Taxonomic chauvinism threatens the future of Entomology. Biologist 56: 10-13.

Legendre, P. and Anderson, M. J. (1999). Distance-based redundancy analysis: testing multispecies responses in multifactorial ecological experiments. Ecological Monographs 69: $1-24$

Legendre P. and Legendre, L. (2012). Numerical Ecology, $3^{\text {rd }}$ edn. Elsevier: Amsterdam

Leung, A. S. L.; Li, A. O. Y. and Dudgeon, D. (2012). Scales of spatiotemporal variation in macroinvertebrate assemblage structure in monsoonal streams: the importance of season. Freshwater Biology 57:218-231

Masese, F. O.; Kitaka, N. and Kipkemboi, J. (2014) Macroinvertebrate functional feeding groups in Kenyan highland streams: evidence for a diverse shredder guild. Freshwater Science 33:435-450

Merritt, R. W. and Cummins, K. W. (1996). An introduction to the aquatic insects of North America (3rded.). IOWA, Dubuque: Kendall-Hunt.

Mesa, L. M. (2010) Effect of spates and land use on macroinvertebrate community in Neotropical Andean streams. Hydrobiologia 641: 85-95.

Mesa, L. M. (2012). Interannual and Seasonal Variability of Macroinvertebrates in Monsoonal Climate Streams. Brazilian Archives of Biology and Technology 55: 403-410

Mustonen, K. R.; Mykrä, H.; Louhi, P.; Markkola, A.; Tolkkinenm, M.; Huusko, A.; Alioravainen, N.; Lehtinen, S. and Muotka, T. (2016) Sediments and flow have mainly independent effects on multitrophic stream communities and ecosystem functions. Ecology and Application 26: 2116-2129

Poff, N. L. and Zimmerman, J. K. H. (2010). Ecological responses to altered flow regimes: a literature review to inform the science and management of environmental flows. Freshwater Biology 55:194-205

Ricklefs, R. E. and Schluter, D. (2013). Species diversity: regional and historical influences. Species Diversity in Ecological Communities. Historical and Geographical Perspectives (eds R.E. Ricklefs \& D. Schluter), pp. 350- 363. Chicago: University of Chicago Press. 
Sharifinia, M.; Namin, J. and Makrani, A. (2012). Benthic Macroinvertebrrate Distribution in Tajan River Using Canonical Correspondence Analysis. Caspian Journal of Environmental Science 10: 181-194

Si, X.; Baselga, A.; Leprieur, F.; Song. X. and Ding, P. (2016). Selective extinction drives taxonomic and functional alpha and beta diversities in island bird assemblages. Journal of Animal Ecology 85: 409-418.

Socolar, J. B.; Gilroy, J. J.; Kunin, W. E. and Edwards, D. P. (2016). How should beta-diversity inform biodiversity conservation? Trends in Ecology and Evolution 31: 67-80.

Soininen, J.; Heino, J. and Wang, J. (2017). A meta-analysis of nestedness and turnover components of beta diversity across organisms and ecosystems. Global Ecology and Biogeography DOI: 10.1111/geb.12660

Tisseuil, C.; Leprieur, F.; Grenouillet, G.; Vrac, M. and Lek, S. (2012). Projected impacts of climate change on spatio-temporal patterns of freshwater fish beta diversity: A deconstructing approach. Global Ecology and Biogeography 21:12131222.

Tonkin, J. D.; Arimoro, F. O. and Haase, P. (2016). Exploring stream communities in a tropical biodiversity hotspot: biodiversity, regional occupancy, niche characteristics, and environmental correlates. Biodiversity and Conservation 25: 975-993

Viana, D. S.; Figuerola, J.; Schwenk, K.; Manca. M.; Hobæk. A.; Mjelde, M. and Santamaría, L. (2016). Assembly mechanisms determining high species turnover in aquatic communities over regional and continental scales. Ecography 39:281288.

Vinson, M. R. and Hawkins, C. P. (2003). Broad-scale geographical patterns in local stream insect genera richness. Ecography 26:751-767.

Ward, J. V. (1992). Aquatic Insects ecology. NewYork: John Wiley and Sons Inc. 